\title{
RESUMEN DE TESIS
}

Antonio Tobón Restrepo. Trillar para festejar: Tiempo de hacer y usar música en Chile central republicano. Santiago: Universidad de Chile, Facultad de Artes, Magíster en Artes, mención Musicología, 2008, 180 pp. Profesor guía: Víctor Rondón Sepúlveda.

En Chile, a lo menos desde 1850, el desarrollo de la economía triguera de exportación supuso el ordenamiento de la sociedad del gran latifundio tradicional. Este trabajo se ocupa de la construcción social dada por las relaciones entre individuos, en un momento preciso, aquel de la cosecha. La trilla, faena última de este proceso -en la que se separa el grano del trigo de la espiga- era, además, una ocasión festiva de congregación de todas las gentes del campo. La respuesta a la pregunta por qué era ésta una ocasión festiva o qué la hacía un momento especial para la sociedad agricultora, es central en la observación que en esta tesis se hace de la música como cultura.

La observación de las dimensiones simbólicas de la música en esta ocasión aparece estrechamente ligada con los sentidos y significados inmanentes en el tiempo en el que sucede la trilla y la organización de la sociedad para hacerla.

Desde la historia cultural aborda una serie de problemas que atañen, especialmente a la estructura de la música y los músicos, pero, sobre todo, a las dimensiones simbólicas presentes en el hacer y usar la música como dinámicas sociales.

Dos conceptos son claves en la elaboración de la respuesta de tal pregunta, que a su vez estructuran el escrito en dos partes.

Los problemas que instala.

La base del trabajo que resultó en esta tesis fue la pregunta sobre cómo se usaba y hacía música en el mundo hacendal triguero de Chile central durante el siglo XIX. Quizá la pregunta la gatilla la instituida premisa del cambio en el uso de una música de acuerdo al cambio en el contexto en el que ella cumple determinadas funciones, pero también es gatillada por el intento de abordar la relación Historia-Musicología.

Antonio Tobón Restrepo

Magíster en Artes, mención M usicología

Facultad de Artes, Universidad de Chile antonio.tobon@gmail.com

Omar Percy Ponce Valdivia. De charango a chillador. Confluencias musicales en la estudiantina altiplánica. Universidad de Chile, Facultad de Artes, Magíster en Artes, mención Musicología, 2008, 178 pp. Profesor guía: Rodrigo Torres Alvarado.

Los textos surgidos desde la tercera década del siglo XX han configurado un imaginario homogéneo y generalizador respecto a la práctica musical en las comunidades andinas. En referencia al charango, estos escritos han instalado ideas comunes acerca de las características, la música y el contexto indígena del instrumento. En este marco, tales descripciones o definiciones del charango, generadas por el discurso etnográfico del siglo XX, dan luces a una problemática de interés musicológico, cual es la construcción de identidades socioculturales y territoriales asignadas al instrumento y a sus prácticas musicales.

La tesis analiza, en la práctica actual del charango, cómo más allá de tales pertenencias o identidades narradas, las músicas del instrumento han devenido en una transcontextualidad, en la cual se reafirma la coexistencia de variantes instrumentales en correspondencia con la heterogeneidad del universo musical andino y sus situaciones. Este proceso es entendido como una refuncionalización del instrumento a los procesos de representatividad local que surgen en la práctica musical de comunidades inmigrantes en los espacios urbanos. La investigación está ubicada en el Altiplano del Collao y se focaliza en el departamento de Puno, en Perú, luego de estudiar los marcos rituales y sociales que articulan los distintivos musicales locales, abordando las músicas de Kjaswa de Capachica y Q'ajjelo,

Revista M usical Chilena, Año LXIII, Julio-Diciembre, 2009, N²12, pp. 143-146 
respectivamente. Se estudian aspectos de la performance del charango pertinentes a desentrañar cómo estos distintivos, traducidos en modalidades de ejecución y variantes instrumentales, son incorporados a una práctica urbana cuyo principal espacio musical y social es la Estudiantina altiplánica.

Tomando el caso del Q'ajjelo, analizamos la confluencia de ciertos caracteres sonoros primigenios en una música de funciones representativas y simbólicas de lo local, elaborada para los espacios de performance urbana y para la discografía; la denominada Captación. En tanto que el universo instrumental de la estudiantina es mixto y "moderno", el charanguista ejecuta un bagaje musical que sintetiza lo colectivo primigenio, sus caracteres musicales se constituyen en elementos semánticos que actúan en el reconocimiento de una música como "altiplánica". Es en distinción musical de lo altiplánico, en que se configura la variante instrumental del charango llamado Chillador; un denominativo hispano que connota la mirada hacia la expresión indígena, cuya incorporación a la música urbana es analizada en términos de fricción entre musicalidades de raíz indígena y otras de tendencia "moderna" o urbana.

El enfoque analítico postula una comprensión de la cultura local como un proceso, en el cual las músicas son transformadas a la vez que actualizadas. Desde este caso es posible constatar que el proceso musical del siglo XXI configura nuevas modalidades, en función a los espacios transculturales de práctica. Una de estas constataciones es que la música de la estudiantina altiplánica, generada en la interacción con la matriz primigenia del charango, ha significado en el Altiplano puneño un rompimiento de la dicotomía culto-folclórico. Asimismo, el proceso de confluencias observado en el paso de Charango a Chillador neutraliza las adscripciones territoriales que señalaba el discurso etnográfico del siglo XX respecto a una pertenencia exclusivamente campesina del instrumento, referido, además, como "un" instrumento. Las construcciones narrativas correspondían a una mirada étnica que ubicaba lo "indio" como un sustrato inaccesible al mundo moderno, asunción que es deconstruida por la existencia actual de músicas y espacios de práctica, en las que la interacción del charango cumple un rol relevante.

Omar Ponce Valdivia

M agíster en Artes, mención M usicología Facultad deArtes, Universidad de Chile omarponce73@hotmail.com

Álvaro Menanteau Aravena. M odernidad, posmodernidad eidentidad del jazz en Chile: el caso dela generación de 1990 y Ángel Parra. Helsinki: Universidad de Helsinki, Facultad de Artes, Departamento de Musicología, 2009, 182 pp. Profesor guía, Dr. Alfonso Padilla.

Este trabajo (conducente al grado de Doctor en Musicología) investiga la historia del jazz en Chile a la luz de las problemáticas de modernidad e identidad, con particular énfasis en la joven generación de jazzistas chilenos activos entre 1987 y 2008 . El estudio de la modernidad lleva a considerar aspectos de la posmodernidad y la globalización, mientras que el análisis de la identidad está focalizado en la sociedad latinoamericana y, particularmente, en la sociedad chilena.

Esta tesis está articulada a partir de un enfoque musicológico, cruzado por aportes tomados de la historia y la sociología. Se da cuenta de las diferentes etapas en la historia del jazz en Chile para luego pesquisar las opciones estéticas y la formación profesional de los exponentes de la generación de los años 90, y finalmente centrarse en la trayectoria musical de su primer representante, el guitarrista y compositor Ángel Parra Orrego (=Ángel Cereceda Orrego, n. 1966). Además, se establecen las características generales de esta generación respecto de su producción musical, discografía y circuito de difusión.

La denominada 'generación de los 90' representa una importante renovación en la escena jazzística de Chile, debido particularmente a su calidad técnica superior -principalmente a nivel instrumentalque, como colectivo, no se encuentra en ninguna generación local anterior, además de su prolífica producción discográfica, en la que abunda la composición original. Al mismo tiempo, se caracteriza por una desconexión con el pasado jazzístico local, de modo tal, que ese pasado no constituye un referente para estos músicos nacionales, como había ocurrido hasta ese momento.

Dentro de esta generación, la evolución de Ángel Parra es particularmente interesante, ya que su debut en el medio jazzístico chileno lo hace integrándose de manera directa a la vanguardia del jazz rock en boga a fines de los años 80 . Con posterioridad realiza un recorrido hacia atrás en cuanto a sus 